\title{
Nuclear GSK3 $\beta$ induces DNA double-strand break repair by phosphorylating 53BP1 in glioblastoma
}

\author{
YONG YANG ${ }^{1-3^{*}}$, TIANTIAN LEI ${ }^{3 *}$, SUYA DU $^{3 *}$, RONGSHENG TONG ${ }^{2,3}$, HAILIAN WANG ${ }^{4}$,

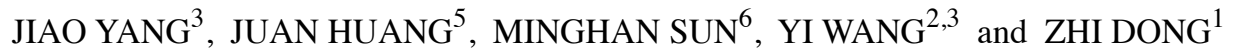 \\ ${ }^{1}$ Chongqing Key Laboratory of Biochemistry and Molecular Pharmacology, College of Pharmacy, \\ Chongqing Medical University, Chongqing 400016; ${ }^{2}$ Personalized Drug Therapy Key Laboratory of Sichuan Province, \\ Department of Pharmacy, Sichuan Academy of Medical Science and Sichuan Provincial People's Hospital, Chengdu, \\ Sichuan 610072; ${ }^{3}$ School of Medicine, University of Electronic Science and Technology of China, Chengdu, \\ Sichuan 610054; ${ }^{4}$ Institute of Organ Transplantation, Sichuan Academy of Medical Science and \\ Sichuan Provincial People's Hospital, Chengdu, Sichuan 610072; ${ }^{5}$ Department of Pharmacy, Medical Center Hospital of \\ Qionglai, Qionglai, Sichuan 611500; ${ }^{6}$ Department of Gynecology, Sichuan Academy of Medical Science \\ and Sichuan Provincial People's Hospital, Chengdu, Sichuan 610072, P.R. China
}

Received September 7, 2017; Accepted December 20, 2017

DOI: 10.3892/ijo.2018.4237

\begin{abstract}
Glioblastoma is the most malignant and lethal subtype brain tumors with high risk of recurrence and therapeutic resistance. Emerging evidence has indicated that glycogen synthesis kinase 3 (GSK3) $\beta$ plays oncogenic roles in multiple tumor types; however, the underlying mechanisms remain largely unknown. It has also been demonstrated that $\mathrm{p} 53$ binding protein 1 (53BP1) plays a central role in DNA double-strand break (DSB) repair. This study aimed to reveal the significance of GSK3 $\beta$ translocation from the cytoplasm to the nucleus, and to determine whether GSK $3 \beta$ induces DNA DSB repair in the nuclei of glioblastoma cells via phospho-53BP1. By performing in vitro experiments, we found that GSK $3 \beta$ translocated from the cytoplasm to the nucleus, and it then bound to 53BP1 following exposure to IR (IR). In addition, 53BP1-mediated DNA DSB repair was observed to be abrogated by the inhibition of GSK3 $\beta$. Further experiments on the phosphorylation site of 53BP1 by GSK $3 \beta$ revealed that the S/T-Q motif may play a critical role.
\end{abstract}

Correspondence to: Dr Zhi Dong, Chongqing Key Laboratory of Biochemistry and Molecular Pharmacology, College of Pharmacy, Chongqing Medical University, 1 Yixueyuan, Yuzhong, Chongqing 400016, P.R. China

E-mail: dongzhi0326@126.com

Dr Yi Wang, Personalized Drug Therapy Key Laboratory of Sichuan Province, Department of Pharmacy, Sichuan Academy of Medical Science and Sichuan Provincial People's Hospital, 32 West Ring Road, Chengdu, Sichuan 610072, P.R. China

E-mail:w_yi@yahoo.com

*Contributed equally

Key words: glioblastoma multiforme, p53 binding protein 1, glycogen synthesis kinase 3
Importantly, our in vivo and in vitro data clearly indicated that GSK3 $\beta$ induced the phosphorylation of 53BP1 at the Ser166 site. Moreover, brain tumor xenograft models revealed that following exposure to IR plus SB216763, a specific GSK3 $\beta$ inhibitor, tumor growth was markedly inhibited and the survival of mice markedly increased. Based on these results, we concluded that the phosphorylation of 53BP1 by GSK3 $\beta$ was indispensable for DNA DSB repair. Our study also suggested that the inhibition of GSK3 $\beta$ by SB216763 significantly inhibited the proliferation and induced the apoptosis of glioblastoma cells. Taken together, our data indicate that GSK3 $\beta$, a key phosphorylation protein for 53BP1, may be a potential target for enhancing the sensitivity of glioblastoma cells to radiation.

\section{Introduction}

Glioblastoma multiforme (GBM), a neoplasm of the central nervous system (CNS), is a highly aggressive and the most malignant subtype of glioma (1). Attention was drawn to GBM due to its poor 2-year survival rate and high mortality rate. Although radiotherapy following surgical resection of the tumor remains the most effective treatment for GBM, this is still palliative as the majority of tumors recur (2). Various factors, including vasculogenesis, contribute to the recurrence (3-5). Among these, the main explanation for recurrence is the activation of DNA double strand break (DSB) repair following ionizing radiation (IR) (6). Evidence has accumulated over the past decade indicating that $\mathrm{p} 53$ binding protein 1 (53BP1) plays a central role in response to DNA damage recognition and repair $(7,8)$. Moreover, the robust silencing of the 53BP1 gene sensitizes glioma cells to IR both in vitro and in vivo, suggesting the critical role of 53BP1 in radiotherap (9). Thus, molecules targeting the regulation of 53BP1 phosphorylation and activation may provide a therapeutic strategy with which to combat radioresistance. Studies on the structure of 53BP1 have revealed 3 highly conserved domains of 53BP1, 
namely the BRCA1 carboxy-terminal (BRCT) repeats, the tandem tudor domain and 28 amino-terminal Ser/Thr-Gln (S/T-Q) sites. Upon IR, the S/T-Q site of 53BP1 is partially phosphorylated by the ataxia-telangiectasia mutated (ATM) kinase $(7,10)$. Therefore, the question of whether there are other factors regulating the phosphorylation and activation of 53BP1 remains unresolved.

There is emerging evidence to suggest that glycogen synthase kinase $3 \beta$ (GSK3 $\beta$ ), a multifunctional serine/ threonine kinase, is a key regulator of numerous signaling pathways, such as cell cycle control, proliferation, differentiation and apoptosis $(11,12)$. Increasing knowledge has revealed the intriguing regulatory role of GSK3 $\beta$ in a diverse array of prevalent diseases, such as hypertrophy, diabetes and Alzheimer's disease $(13,14)$. Previous studies on tumors have suggested that GSK $3 \beta$ is one of the driving forces behind tumorigenesis $(15,16)$ and it plays critical role in multiple tumor types (17-19). Described as a tumor-promoting factor, GSK3 $\beta$ is interconnected with several critical pathways associated with tumors, such as the Wnt/ $\beta$-catenin (19) and PI3K/PTEN pathways (20). In glioblastoma, studies have indicated the oncogenic role of GSK3 $\beta$ (21,22). More importantly, nuclear GSK $3 \beta$ is of particular interest as it regulates a number of transcription factors and is deemed to be a hallmark of highgrade tumors $(23,24)$.

In this study, our findings demonstrated that IR induced the nuclear translocation of GSK3 $\beta$, which was responsible for the activation of 53BP1, a key DNA damage response protein. Furthermore, a high level of nuclear GSK3 $\beta$ sensitized glioblastoma cells to IR via the phosphorylation of 53BP1 at serine 166. In vivo experiments revealed that the inhibition of GSK3 $\beta$ following IR may lead to a decreased tumor volume and an increased survival rate. Therefore, SB216763, a GSK3 $\beta$ specific inhibitor, may overcome radioresistance and may provide a therapeutic strategy for malignant brain tumors.

\section{Materials and methods}

Reagents, kits and antibodies. The GSK3 specific inhibitor, SB216763 (Cat. no. S3443), 3-(4,5-dimetrylthiazol-2-yl)-2, 5-diphenyltetrazolium bromide (MTT, Cat. no. M5655), dimethyl sulfoxide (DMSO, Cat. no. D2650), paraformaldehyde (PFA, Cat. no. 16005), DAPI (Cat. no. D9542), protein A sepharose (Cat. no. P3391), HEPES (Cat. no. H3375), Triton X-100 (Cat. no. H9284), $2 \mathrm{mmol} / 1$ sodium orthovanadate (Na3VO4; Cat. no. S6508), sodium fluoride (Cat. no. S7920), $1 \mathrm{mmol} / 1$ edetic acid (Cat. no. E9884), PMSF (Cat. no. 78830), aprotinin (Cat. no. A11530), leupeptin (Cat. no. L2884) and rabbit polyclonal anti-Flag antibody (Cat. no. F7425) were purchased from Sigma-Aldrich (St. Louis, MO, USA). KU-55933 (Cat. no. S1092) was purchased from Selleck Chemicals (Houston, TX, USA). Rabbit polyclonal Mre11 antibody (Cat. no. 4895) was purchased from Cell Signaling Technology (Danvers, MA, USA). [ $\gamma$-P32]ATP was purchased from Perkin-Elmer (Foster City, CA, USA). The nuclear and cytosolic protein extraction kit (Cat. no. AKR-171) was purchased from Cell Biolabs (San Diego, CA, USA). Mouse monoclonal GSK3 $\beta$ antibody (Cat. no. ab93926), rabbit polyclonal 53BP1 antibody (Cat. no. ab36823), rabbit polyclonal $\gamma$-H2AX (phosphor-S139) antibody (Cat. no. ab11174) and rabbit polyclonal GST antibody (Cat. no. ab19256) were purchased from Abcam (Cambridge, MA, USA). Mouse monoclonal Lamin A antibody (Cat. no. sc-7292), mouse monoclonal $\beta$-actin antibody (Cat. no. sc-47778) were purchased from Santa Cruz Biotechnology, Inc. (Santa Cruz, CA, USA). Mouse monoclonal NBS1 antibody was purchased from Novus Biologicals (Littleton, CO, USA). Horseradish peroxidase (HRP)-conjugated goat anti-mouse IgG polyclonal antibody (Cat. no. 115-035-003), HRP-conjugated goat anti-rabbit polyclonal IgG (Cat. no. 111-035-003), FITC-conjugated goat anti-mouse IgG polyclonal antibody (Cat. no. 115-005-003) and FITC-conjugated goat anti-rabbit IgG polyclonal antibody (Cat. no. 111-095-003) were purchased from Jackson ImmunoResearch Laboratories (West Grove, PA, USA).

Cell culture, cell survival and DNA damage assay. The human glioblastoma cell line, U87, was obtained from the American Type Culture Collection (Cat. no. HTB-14; ATCC, Manassas, VA, USA). Short tandem repeat (STR) DNA profiling of the U87 cells was performed using the Cell ID System (Cat. no. G9500; Promega, Madison, WI, USA), indicating that the U87 cells used in this study were from ATCC. Although the U87 cell line from ATCC was not the original cell line from the University of Uppsala (25), the cells are still widely used in the study of glioblastoma $(26,27)$. Previous studies have demonstrated that GSK3 is expressed in primary GBM (28) and U87 (ATCC) cells (24,29). Furthermore, in vivo U87 (ATCC) xenograft glioblastoma mouse model analyses on GSK3 have revealed that the combination of GSK3 inhibitor with carboplatin, a DNA damage-inducing reagent, results in a significantly reduced tumor volume (22). Moreover, U87 cells can be engineered with various expression vectors. Thus, we decided to use the U87 cells from ATCC in this study in both in vitro and in vivo experiments. The cells were cultured in DMEM containing 10\% FBS, $100 \mu \mathrm{g} / \mathrm{ml}$ streptomycin (Life Technologies, Carlsbad, CA, USA), $100 \mathrm{U} / \mathrm{ml}$ penicillin (Life Technologies) and $0.03 \%$ L-glutamine (Sigma-Aldrich).

The U87 cells at logarithmic growth phase were seeded in a 96-well plate and incubated at $37^{\circ} \mathrm{C}$ for $24 \mathrm{~h}$, and GSK3 inhibitor $20 \mu \mathrm{M}$ SB216763 and control solvent were added followed by incubation at $37^{\circ} \mathrm{C}$ for a further $24 \mathrm{~h}$. Subsequently, $0.05 \mathrm{mg}$ (10 $\mu \mathrm{l}$ of $5 \mathrm{mg} / \mathrm{ml})$ MTT was added to each well and incubated at $37^{\circ} \mathrm{C}$ for $4 \mathrm{~h}$, and the medium was then removed followed by shaking thoroughly for $1 \mathrm{~h}$. Finally, termination buffer was added to each well. The absorbance at $570 \mathrm{~nm}$ was measured using a spectrophotometer (Model 3550 Microplate Reader, Bio-Rad Laboratories, Hercules, CA, USA). Cell viability was determined as follows: Cell viability $(\%)=[$ OD $570 \mathrm{~nm}(\mathrm{drug}) / \mathrm{OD} 570 \mathrm{~nm}$ (control) $] \times 100 \%$.

8 -Hydroxy-2'-deoxyguanosine $(8-\mathrm{OHdG})$ is a modified nucleotide base and a by-product of DNA damage that is excreted upon DNA repair. By measuring the levels of 8-OHdG, DNA damage percentages were determined using a commercial ELISA kit (Cat. no. ADI-EKS-350; Enzo Life Sciences, Ann Arbor, MI, USA).

Immunofluorescence staining. The U87 cells were seeded into 6-well culture plate at a density of $4 \times 10^{5}$ cells/well and cultured for $24 \mathrm{~h}$. For the 53BP1 knockdown group, cells were transfected with 5 pM ON-TARGET plus Human 
53BP1 siRNA pool (Cat. no. L-003548-00-0005, Dharmacon, Lafayette, CO, USA) by DharmaFect (Cat. no. T-2001-01, Dharmacon) for $48 \mathrm{~h}$. The cells were fixed with $4 \%$ PFA for $30 \mathrm{~min}$ at room temperature, and then permeabilized by $1 \%$ Triton-X 100. After blocking with 5\% BSA for $1 \mathrm{~h}$ at room temperature, the cells with incubated with primary antibody (mouse monoclonal GSK3 antibody, rabbit polyclonal $\gamma$-H2AX (phospho-S139) antibody and mouse monoclonal NBS1 antibody) overnight at $4^{\circ} \mathrm{C}$. The cells were then incubated with corresponding secondary antibody (FITC-conjugated goat anti-mouse IgG polyclonal antibody and FITC-conjugated goat anti-rabbit IgG polyclonal antibody) for $2 \mathrm{~h}$ at room temperature. After staining with DAPI, the cells were washed and analyzed immediately under a fluorescence microscope (Olympus, Tokyo, Japan). All experiments were carried out in triplicate. Experiments were repeated 3 times, and data are representative of replicate experiments.

Immunoprecipitation. The U87 cells were treated with $20 \mu \mathrm{M}$ SB216763 for $24 \mathrm{~h}$. For the GSK3 $\beta$ knockdown group, cells were transfected with 5 pM ON-TARGET plus Human GSK3 $\beta$ siRNA pool (Cat. no. LU-003010-00-0005, Dharmacon, Lafayette, CO, USA) by DharmaFect (Dharmacon) for $48 \mathrm{~h}$. For the knockdown control group, cells were transfected with 5 pM scramble siRNA (Cat. no. D-001810-10-05, Dharmacon) by DharmaFect (Dharmacon) for $48 \mathrm{~h}$, and the cells were then harvested. The cell pellets were resuspended with lysis buffer and lysed at $4^{\circ} \mathrm{C}$ for $15 \mathrm{~min}$. The lysis buffer consists of $50 \mathrm{mmol} / \mathrm{l}$ HEPES (pH 7.4), 1\% Triton X-100, 2 mmol/1 $\mathrm{Na}_{3} \mathrm{VO}_{4}, 100 \mathrm{mmol} / 1$ sodium fluoride, $1 \mathrm{mmol} / \mathrm{l}$ edetic acid, $1 \mathrm{mmol} / 1 \mathrm{PMSF}, 10 \mathrm{mg} / \mathrm{l}$ aprotinin and $10 \mathrm{mg} / 1$ leupeptin. Following centrifugation at $12,000 \mathrm{x} \mathrm{g}$ for $15 \mathrm{~min}$, the protein content of the supernatant was determined by Bradford protein assay (Cat. no. P0006; Beyotime, Suzhou, China). In addition, protein A Sepharose beads were incubated with GSK $3 \beta$ antibody or 53BP1 antibody at overnight $4^{\circ} \mathrm{C}$. The the cell supernatant was then incubated with $30 \mathrm{mg}$ protein $\mathrm{A}$ Sepharose beads at overnight $4^{\circ} \mathrm{C}$, and performed western blot analysis was performed as described below.

Western blot analysis. The U87 cells were treated with $20 \mu \mathrm{M}$ SB216763 for $24 \mathrm{~h}$. For the GSK3 $\beta$ knockdown group, cells were transfected with 5 pM ON-TARGET plus human GSK3 $\beta$ siRNA pool (Cat. no. LU-003010-00-0005, Dharmacon) by DharmaFect (Dharmacon) for $48 \mathrm{~h}$. For the knockdown control group, cells were transfected with $5 \mathrm{pM}$ scramble siRNA (Cat. no. D-001810-10-05, Dharmacon) by DharmaFect (Dharmacon) for $48 \mathrm{~h}$, and the cells were then collected and the cell pellets were resuspended. Nuclear and cytoplasmic proteins were extracted using the nuclear and cytosolic protein extraction kit (Cat. no. AKR-171; Cell Biolabs) according to the manufacturer's instructions. The protein content was determined by Bradford protein assay. Equal amounts of the total protein were separated by 4-12\% NuPAGE Bis-Tris gels (Cat. no. NP0327BOX, Life Technologies) and transferred onto PVDF membranes (Cat. no. ISEQ00010, Millipore, Bedford, MA, USA), and the membranes were soaked in $5 \%$ BSA (Cat. no. V900933, Sigma-Aldrich). The proteins were then detected using primary (mouse monoclonal GSK $3 \beta$ antibody, rabbit polyclonal 53BP1 antibody, mouse monoclonal
Lamin A antibody, rabbit polyclonal anti-Flag antibody and rabbit polyclonal GST antibody) and secondary antibodies (HRP-conjugated goat anti-mouse IgG polyclonal antibody and HRP-conjugated goat anti-rabbit polyclonal $\mathrm{IgG}$ ), and then visualized with ECL (Cat. no. 345818, Millipore). The experiments were repeated 3 times, and data are representative of replicate experiments.

Plasmids. The cDNA encoding full-length 53BP1 was obtained from the U87 cells by reverse transcription-polymerase chain reaction using a Reverse Transcript System kit (Cat. no. A3500, Promega), and then inserted into the pBluescript bacterial expression vector, which was purchased from Addgene (Cambridge, MA, USA). pGST-53BP1-N1, pGST-53BP1-N2, pGST-53BP1-C1 and pGST-53BP1-BRCT (Fig. 4D) were respectively constructed by ligating a NdeI-EcoRI fragment of full-length 53BP1 to pBluescript. The GST-fused 53BP1 constructs were overexpressed in E. coli BL21 (DE3) cells (Cat. no. CB101, Tiangen Biotech, Beijing, China) by induction with $0.4 \mathrm{mM}$ IPTG, and then purified with glutathione Sepharose beads (GE Healthcare, Piscataway, NJ, USA). Point mutations for the replacement of Ser (S) with Ala (A) were performed by using a Quick Change site-directed mutagenesis kit (Stratagene, La Jolla, CA, USA) and all of the mutations were confirmed by DNA sequencing analysis. Flag tagged 53BP1 was constructed in pcDNA3, and Flag tagged GSK3 was constructed in pBABE-puro.

In vivo phosphorylation assay. For the analysis of 53BP1 labeling with $\left[\gamma_{-}{ }^{32} \mathrm{P}\right] \mathrm{ATP}$, the U87 cells were washed twice with phosphate-free Dulbecco's modified Eagle's medium and subsequently incubated with $15 \mathrm{mCi}\left[\gamma^{-}{ }^{32} \mathrm{P}\right] \mathrm{ATP}$ for $3 \mathrm{~h}$.

For irradiation of the cells, the cells were irradiated with a calibrated Shepherd and Associates Mark I self-shielded ${ }^{137} \mathrm{Cs}$ y irradiator (JL Shepherd and Associates Inc., San Fernando, CA, USA), at a dose rate of $1.84 \mathrm{~Gy} / \mathrm{min}$. As a control, the mock irradiation ( $0 \mathrm{~Gy}$ ) was performed by placing the plates containing cells in the irradiator for the designated time period without turning on the machine. Following stimulation of the cells with 5 Gy IR, we immunoprecipitated GSK3 $\beta$ or 53BP1 as described previously. For treatment with $\lambda$-PPase (Cat. no. B0753S, New England Biolabs, Beverly, MA, USA), the cells were washed in ice-cold PBS and harvested in $\lambda$-PPase buffer supplemented with protease inhibitors. The cells were then sonicated on ice (Sonicator 4000, Misonix, Farmingdale, NY, USA), and treated with 800 units $\lambda$-PPase for $30 \mathrm{~min}$ at $30^{\circ} \mathrm{C}$. The proteins were separated by $4-12 \%$ NuPAGE Bis-Tris gels and scanned on a Typhoon phosphorimager (Typhoon 9200 instrument, GE Healthcare Sciences).

In vitro phosphorylation assay. The Flag-tagged GSK3 vector (Camod Biological, Beijing, China) was transfected into 293T cells (ATCC, Manassas, VA, USA ) using Lipofectamine 2000 and Opti-MEM (both from Life Technologies). At $48 \mathrm{~h}$ after transfection, the cells were lysed by sonication in $50 \mathrm{mM}$ Tris-HClbuffer ( $\mathrm{pH} 7.5)$ containing $50 \mathrm{mM} \beta$-glycerophosphate, $150 \mathrm{mM} \mathrm{NaCl}, 10 \%$ glycerol, $1 \%$ Tween-20, $1 \mathrm{mM} \mathrm{NaF}, 1 \mathrm{mM}$ $\mathrm{Na}_{3} \mathrm{VO}_{4}, 1 \mathrm{mM}$ PMSF, $2 \mathrm{mg} / \mathrm{ml}$ aprotinin, $2 \mathrm{mg} / \mathrm{ml}$ leupeptin and $1 \mathrm{mM}$ DTT. Following centrifugation at 10,000 $\mathrm{x} \mathrm{g}$ for 10 min, Flag-tagged proteins were immunoprecipitated 
with anti-Flag M2 antibodies (Sigma-Aldrich) and protein A Sepharose. Immunoprecipitated Flag tagged GSK3 $\beta$ was bound to protein A Sepharose and $1 \mu \mathrm{g}$ of GST-53BP1 fragment substrates described above in $20 \mathrm{mM}$ Hepes ( $\mathrm{pH} 7.4$ ), $10 \mathrm{mM} \mathrm{MgCl}_{2}, 10 \mathrm{mM} \mathrm{MnCl}_{2}, 25 \mathrm{mM}$ ATP, and $15 \mathrm{mCi}\left[\gamma_{-}{ }^{32} \mathrm{P}\right]$ ATP for $30 \mathrm{~min}$ at $30^{\circ} \mathrm{C}$. The phosphorylated 53BP1 proteins were separated by $4-12 \%$ NuPAGE Bis-Tris gels and scanned on a Typhoon phosphorimager (Typhoon 9200 instrument, GE Healthcare Sciences).

Tumor xenograft model. To establish tumor xenografts, $5 \times 10^{6} \mathrm{U} 87$ cells were injected into BALB/c nude male mice (5-6 weeks old, 16-18 g body weight, purchased from the Affiliated Laboratory Animal Center of Sichuan Academy of Medical Science and Sichuan Provincial People's Hospital, Chengdu, China). Following implantation, the tumors were allowed to grow to a size of $100-550 \mathrm{~mm}^{3}$. No mouse bearing multiple tumors was found in our study. The mice are randomly divided into 4 groups ( $\mathrm{n}=80$ in total and $\mathrm{n}=20$ per group) as follows: i) the control group, in which mice with U87-derived tumors were left untreated; ii) the IR group, in which mice received IR 25 Gy following tumor formation by U87 cells; iii) the SB216763 group, in which mice were intraperitoneally administered $5 \mathrm{mg} / \mathrm{kg} \mathrm{SB} 216763$ following tumor formation by U87 cells; iv) the SB216763 + IR group, in which mice intraperitoneally were administered $5 \mathrm{mg} / \mathrm{kg} \mathrm{SB} 216763$ and subjected to IR 25 Gy following tumor formation by U87 cells. Following treatment, mouse body weight was measured every 2 days. Subsequently, 10 mice in each group were sacrificed, and 10 mice in each group were used for survival analysis. The subcutaneous tumors were removed from the sacrificed mice, weighed and fixed for immunofluorescence staining described above. In brief, tumors were fixed in $10 \%$ formalin (Cat. no. HT-5011, Sigma-Aldrich) for $24 \mathrm{~h}$ at room temperature, dehydrated, embedded in paraffin (Cat. no. A601888, Sangon Biological, Shanghai, China) and sectioned $(5 \mu \mathrm{m})$. To detect the apoptosis, transferase-mediated dUTP nick-end labeling (TUNEL) staining was performed using Roche fluorescence Dead End kit (Cat. no. 11684795910, Roche Diagnostics, Indianapolis, IN, USA) according to the manufacturer's instructions. The cells were analyzed and images were captured using a fluorescence microscope (Nikon Eclipse 80i, Nikon, Tokyo, Japan). In addition, the volume of the tumors was determined in 3 dimensions with venire calipers according to the following formula: Tvol = length $\mathrm{x}$ width $\mathrm{x}$ depth $\mathrm{x} 0.5$. Animal handling was in accordance with the Ethics Committee of Sichuan Academy of Medical Science and Sichuan Provincial People's Hospital, and all animals were kept in a $12 \mathrm{~h}$ light/dark cycle with free access to water and food $\left(26^{\circ} \mathrm{C}\right.$ and $40-60 \%$ humidity), which is in accordance with IVC requirements at the Sichuan Academy of Medical Science and Sichuan Provincial People's Hospital.

Statistical analysis of the data. All data are expressed as means \pm SEM from at least 3 independent experiments. Statistical significance between multiple groups was determined by ANOVA with a Bonferroni post-hoc test, and between 2 groups using a Student's t-test. Survival analyses were carried out using Kaplan-Meier curves. The experiments were repeated 3 times, and data are representative of replicate experiments. A value of $\mathrm{P}<0.05$ was considered to indicate a statistically significant difference.

\section{Results}

Nuclear translocation of GSK3 $\beta$ and its binding with 53BP1. Based on the previous data indicating that GSK3 $\beta$ mRNA and protein levels are increased in glioblastoma (28), we hypothesized that the inhibition of GSK3 $\beta$ may enhance the sensitivity of U87 cells to IR. As predicted, the proliferation rates of the U87 cells treated with $20 \mu \mathrm{M} \mathrm{SB} 216763$, a specific GSK3 $\beta$ inhibitor, were significantly decreased (Fig. 1A), indicating that the inhibition of GSK3 $\beta$ may be a potential radiosensitive therapeutic method in the treatment of GBM after IR. Accumulating evidence indicates that GSK $3 \beta$ is predominantly a cytosolic protein in glioblastoma cells and that nuclear GSK3 $\beta$ promotes tumorigenesis in glioblastoma stem cells (30). Therefore, in this study, to ascertain the distribution of GSK $3 \beta$ in glioblastoma cells, we performed western blot analysis using the U87 cells. As shown in Fig. 1B, 5 of the cells exposed to Gy IR had a higher expression level of GSK3 $\beta$ in the nucleus compared with that of the control cells. Furthermore, the results were validated by immunofluorescence staining of the glioblastoma cells upon exposure to IR; GSK $3 \beta$ was found present in the nucleus following the exposure of the cells to 5 Gy IR (Fig. 1C). Taken together, our findings indicated that IR was able to promote the translocation of GSK3 $\beta$ from the cytosol to the nucleus in U87 cells.

As it has been reported that nuclear GSK3 $\beta$ promotes tumorigenesis in glioma stem cells and regulates several transcription factors, we hypothesized that it may bind with nuclear protein 53BP1, a key regulator in DSB repair, to initiate recurrence. To elucidate the mechanisms responsible for GSK3 $\beta$-mediated DNA DSB repair, a series of immunoprecipitation experiments were performed. As shown in Fig. $2 \mathrm{~A}, 1 \mathrm{~h}$ following exposure to $5 \mathrm{~Gy}$ IR, the nuclear shift of GSK $3 \beta$ contributed to the binding with 53BP1, and ultimately led to DNA DSB repair, which was chemically abrogated by SB216763, a specific GSK3 inhibitor. As shown in Fig. 2B, the binding of GSK3 $\beta$ with 53BP1 was also abolished by the silencing of GSK $3 \beta$ by siRNA, indicating that following exposure to 5 Gy IR, GSK $3 \beta$ translocates to the nucleus, binds to 53BP1 and further initiates DNA DSB repair.

Inhibition of GSK3 $\beta$ abolishes 53BP1-mediated DSB repair. As discussed above, as SB216763, a specific GSK3 $\beta$ inhibitor, evidently decreased the proliferation rates of the U87 cells, and the translocation of GSK $3 \beta$ into the nucleus was followed by binding to 53BP1 and subsequently DSB repair, we evaluated whether the inhibition of GSK $3 \beta$ would abolish 53BP1-mediated DSB repair. As shown in Fig. 3A, accompanied by the inhibitory effects of SB216763 and GSK $3 \beta$ siRNA on GSK3 $\beta$, DSB repair key factors, including $\gamma$-H2AX, Mre11 and NBS1 were dispersed in the nucleus, indicating that the inhibition of GSK3 $\beta$ did not induce the formation of the MRN complex, which is indispensable for DSB repair (31). The results were further confirmed though the assessment of DNA damage percentages and proliferation rates. DNA damage percentages were significantly increased (Fig. 3B), while the proliferation rates were markedly decreased (Fig. 3C) 
A

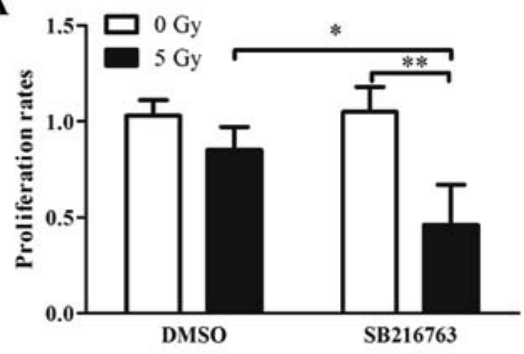

B

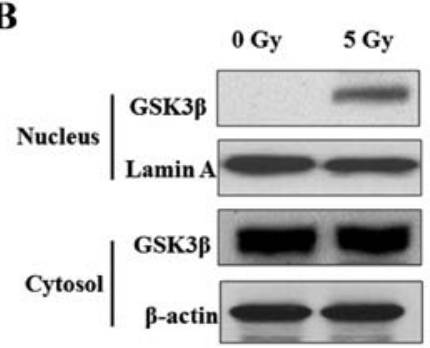

C
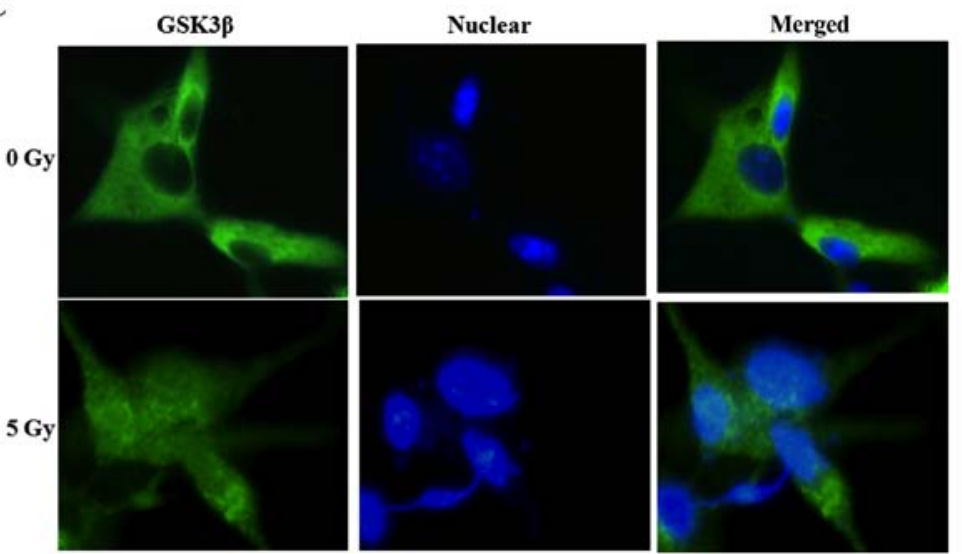

Figure 1. GSK3 $\beta$ translocates into nucleus following ionizing radiation (IR). (A) Proliferation rates of U87 cells treated with SB216763 (GSK3 $\beta$ inhibitor); ${ }^{*} \mathrm{P}<0.05$ vs. the control. Data are the means \pm SEM from 3 independent experiments. (B) Expression level of GSK3 $\beta$ in the nucleus and cytosol following treatment with IR. (C) Immunofluorescence staining images of GBM cells with or without treatment with IR.

A

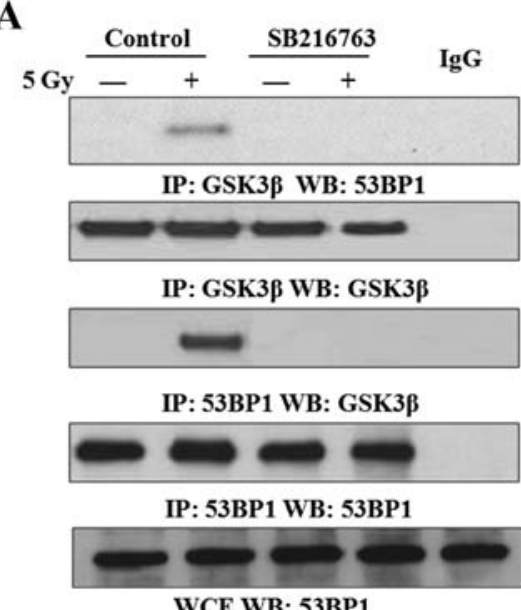

B

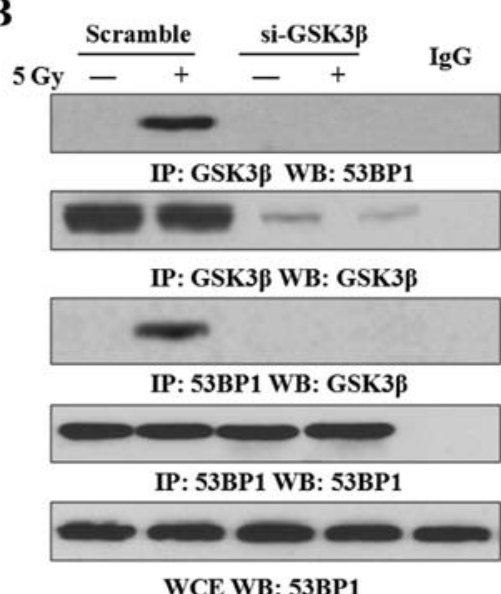

Figure 2. GSK3 $\beta$ binds with 53BP1 upon exposure to ionizing radiation (IR). Co-immunoprecipitation of GSK3 $\beta$ with 53BP1 was performed by protein A/G beads incubated with anti-GSK3 $\beta$ antibody, and western blot analysis was then performed to detect the immunoprecipitated 53BP1 with anti-53BP1 antibody. With the addition of GSK3 $\beta$ specific inhibitor (A) SB216763 and (B) siRNA, the binding of 53BP1 with GSK3 $\beta$ was abolished. Co-immunoprecipitation of 53BP1 with GSK3 $\beta$ was also performed and the GSK3 $\beta$ protein levels were determined by western blot analysis. WCE, whole cell extract.

following treatment of SB21676 or transfection with GSK3 $\beta$ siRNA, suggesting that 53BP1-mediated DSB repair may be abrogated by the inhibition of GSK $3 \beta$.

GSK3 $\beta$ induced the phosphorylation of $53 \mathrm{BP} 1$. It has been previously demonstrated that GSK $3 \beta$ may co-localize with 53BP1, which contains several potential GSK3 $\beta$ phosphorylation sites involving a canonical S/T-Q motif (7), suggesting the phosphorylation and activation of 53BP1 by GSK $3 \beta$. In this study, to address the interactive mechanisms between GSK3 $\beta$ and 53BP1, we observed whether 53BP1 could be phosphorylated endogenously by GSK $3 \beta$ in vivo. As demonstrated in Fig. 4A, 53BP1 was phosphorylated by GSK3 $\beta$ following exposure to 5 Gy IR, which was be abrogated by treatment with SB216763. $\lambda$-PPase, a phosphotransferase inhibitor, also abolished the GSK3 $\beta$-induced phosphorylation of 53BP1. The results were further substantiated in vivo phosphorylation by the silencing of GSK $3 \beta$ by GSK3 $\beta$ siRNA and phosphotransferase 
$\mathbf{A}$
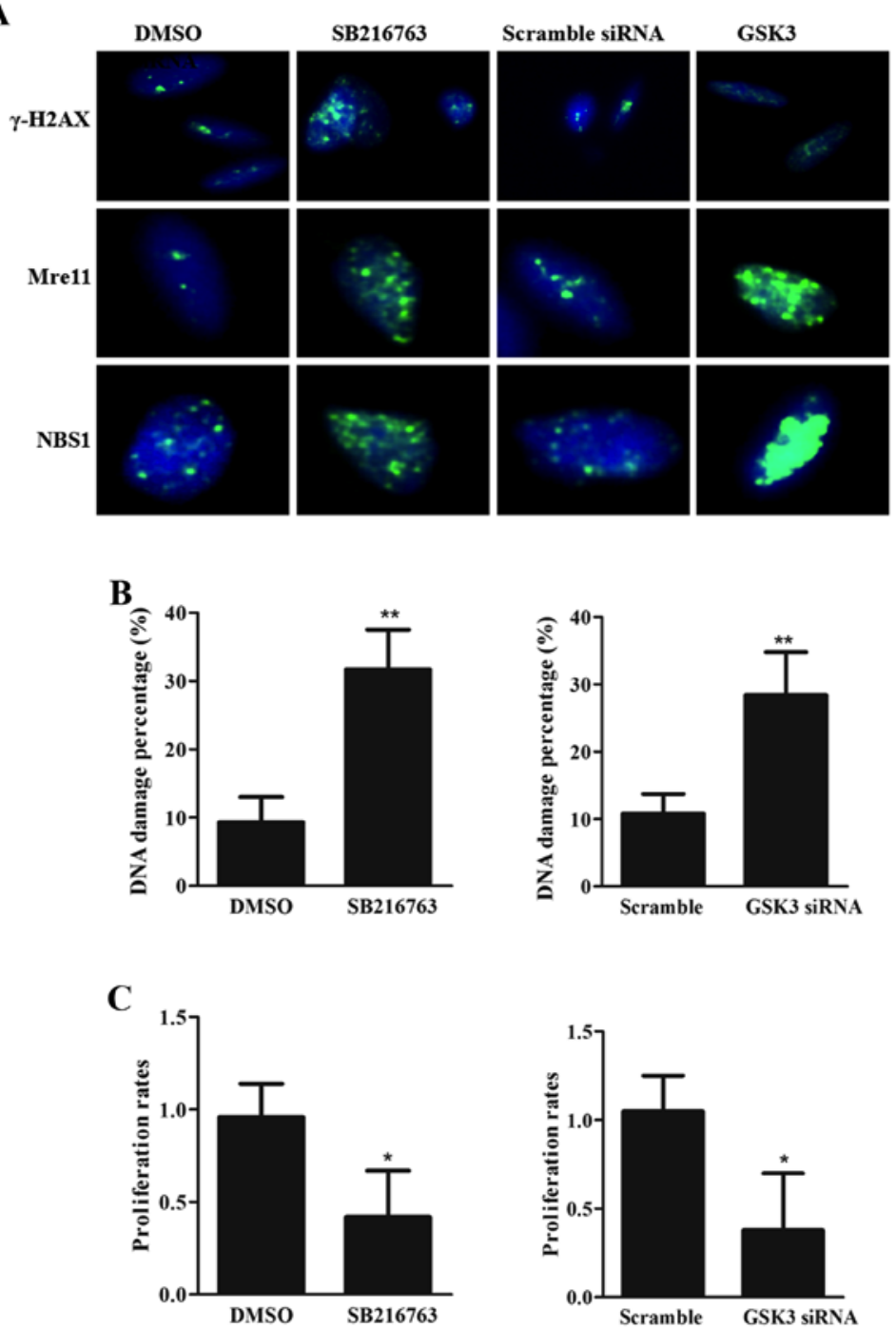

Figure 3. Inhibition of GSK3 abolishes 53BP1-mediated DNA repair. (A) Immunofluorescence staining images of $\gamma$-H2AX, Mre11 and NBS1 in the nucleus of cells treated with control solvent (DMSO), SB216763 (GSK3 $\beta$ inhibitor), scramble siRNA and GSK3 $\beta$ siRNA. (B) DNA damage percentage of U87 cells treated with SB216763 (left panel) and GSK3 $\beta$ siRNA (right panel); ${ }^{* *} \mathrm{P}<0.01$ vs. control. (C) Proliferation rates of U87 cells treated with SB216763 (left panel) and GSK $3 \beta$ siRNA (right panel); ${ }^{P}<<0.05$ vs. control group, as shown by the Student's t-test. Data are the means \pm SEM from 3 independent experiments.

restraint by $\lambda$-PPase (Fig. 4B), and in vitro via the inhibition of GSK3 $\beta$ by SB216763 (Fig. 4C). To characterize the phosphorylation site of 53BP1 in vitro, we generated $\mathrm{NH} 2$-terminal $(\mathrm{N} 1, \mathrm{~N} 2, \mathrm{~N} 3$ and N4) and $\mathrm{COOH}$-terminal (C1 and BRCT) 53BP1 proteins fused with GST (Fig. 4D). The phosphorylation blot was detected when the NH2-terminal 1 (N1) of 53BP1 was used as a substrate. Therefore, it was obvious that the phosphorylation site of 53BP1 is at the N1 fragment via phosphorylation in vivo (Fig. 4E), which was in accordance with phosphorylation in vitro (Fig. 4F). In summary, our in vivo and in vitro phosphorylation data clearly indicated that GSK3 $\beta$ induced the phosphorylation of 53BP1 at the N1 site.

As demonstrated above, GSK3 $\beta$ bound to 53BP1 following its translocation into the nucleus, and GSK $3 \beta$ is critical to 53BP1-mediated DSB repair. Although we found that the phosphorylation domain of 53BP1 may reside at the NH2-terminal, we wished to determine which amino acid was phosphorylated by GSK3 $\beta$. It has been demonstrated that Ser25, Thr302, Ser831, Ser166, Ser176/Ser178 and Ser452 may be potential phosphorylation sites of 53BP1 upon IR treatment (32). In this study (Fig. 4E and F), we demonstrated that the phosphorylation site should be from 1 to 301 amino acids, and Ser25 was a typical ATM phosphorylation site (33); thus, we hypothesized that the phosphorylation sites of 53BP1 may be Ser166 or Ser176/Ser178. Thereby, we mutated Ser166 and Ser176, which are canonical phosphorylation sites, and observed which mutation of 53BP1 may abolish its binding with GSK3 $\beta$. As shown in Fig. 5A, GSK $3 \beta$ bound to 53BP1 in the nucleus without the inhibition of SB216763, and this effect was abrogated by the mutation of 53BP1 at S166A. But for S176A 53BP1, in the absence of GSK $3 \beta$ inhibitor, S176A 53BP1 could still bind with GSK3 $\beta$, indicating that Ser176 was not the phosphorylation site of 53BP1 by GSK3 $\beta$. To address the effects of the S166A mutation, we observed whether the S166A mutation could negatively regulate the phosphorylation of 53BP1. The U87 cells were pre-treated with $10 \mu \mathrm{M} \mathrm{KU}-55933$ for $48 \mathrm{~h}$, and then co-treated with with $20 \mu \mathrm{M} \mathrm{SB} 216763$ for a further $24 \mathrm{~h}$ piror to exposure to IR. We found that the phosphorylation of 53BP1 was abrogated due to the S166A mutation. And for S176A 53BP1, it could still be phosphorylated, revealing that Ser176 was not the 
A

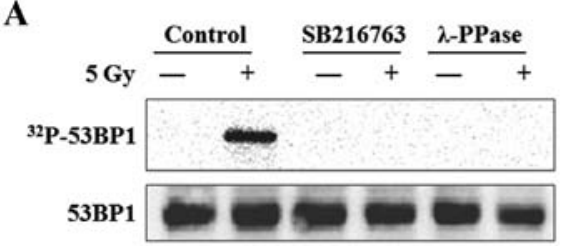

B

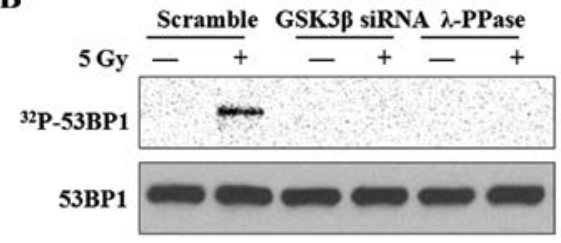

C

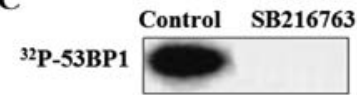

E

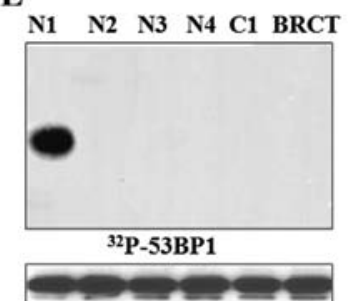

IP: Flag WB: Flag

$\mathbf{F}$

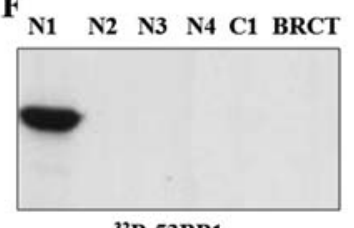

D

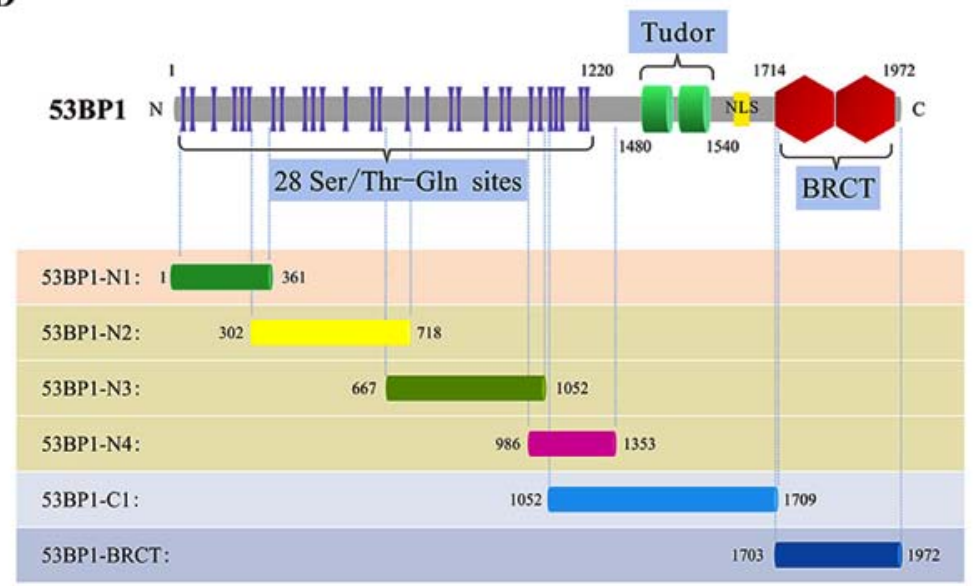

Figure 4. 53BP1 is phosphorylated by GSK3 $\beta$ at the N1 fragment following exposure to IR. (A) In vivo phosphorylation analysis of 53BP1 in the presence of the ATM inhibitor, KU-55933. The phosphorylation of 53BP1 was abrogated by GSK3 $\beta$ inhibitor and abolished by $\lambda$-PPase. (B) In vivo phosphorylation assay of 53BP1 with scramble siRNA or with GSK3 $\beta$ siRNA. (C) In vitro phosphorylation assay of 53BP1 by GSK3 3 . (D) The schematic map of 6 fragments of 53BP1, $\mathrm{N} 1, \mathrm{~N} 2, \mathrm{~N} 3, \mathrm{~N} 4, \mathrm{C} 1$ and BRCT, which were cloned on an expression vector. (E) Endogenous 53BP1 was knocked down by siRNA and the cells were transfected with vectors expressing fragments of 53BP1 as a substrate. In vivo phosphorylation assay was performed to assess the phosphorylation site of 53BP1. (F) GST fused 53BP1 fragments were purified and in vitro phosphorylation was performed.

phosphorylation site of 53BP1 by GSK3 $\beta$ (Fig. 5B). In addition, we mixed GST immobilized mutational 53BP1 proteins with purified Flag tagged GSK3 $\beta$ in the presence or absence of IR, and found that GSK $3 \beta$ could not phosphorylate 53BP1 due to the S166A mutation (Fig. 5C). Taken together, the data above explicitly confirmed that the mutation at S166A abrogated the phosphorylation of 53BP1 by GSK $3 \beta$, and consequently abolished the binding of these two factors.

Mutation at S166A abolishes 53BP1-mediated DSB repair. As mentioned above, 53BP1, primarily exists in the nucleus in GBM cells, and is essential for DSB repair. Therefore, we hypothesized that the mutation of 53BP1 may negatively affect 53BP1-mediated DSB repair. As predicted, DSB repair factors, including $\gamma-\mathrm{H} 2 \mathrm{AX}$, Mre11 and NBS1 were dispersed in the nucleus via the mutation at S166A and the silencing of 53BP1 (Fig. 6A), which suggested the failure of the MRN complex formation, resulting in the restraint of 53BP1-mediated DSB repair. The results were further ascertained through statistical analysis, as shown in Fig. 6B and C. Notably, the cell proliferation rates were decreased, whereas the DNA damage percentages were increased due to the mutation at S166A and the silencing of 53BP1, indicating that the mutation at S166A abolished 53BP1-mediated DSB repair.

Inhibition of GSK3 $\beta$ increases the radiosensitivity of brain tumor xenografts. To examine the effects of GSK3 $\beta$ inhibition on the radiosensitivity of brain tumor xenografts, we examined the growth rates of these tumors with or without SB216763 treatment. As shown in Fig. 7A and B, the calculation of the tumor volume and weight revealed that treatment with SB216763 plus IR markedly inhibited tumor growth compared to treatment with IR treatment alone, SB216763 treatment alone and treatment with normal saline (control); 
A

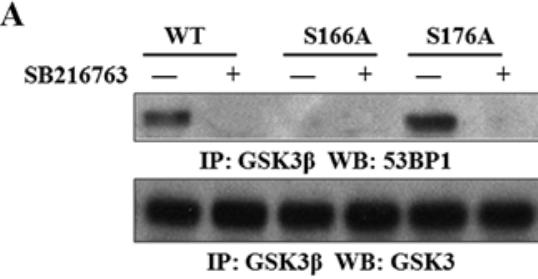

B

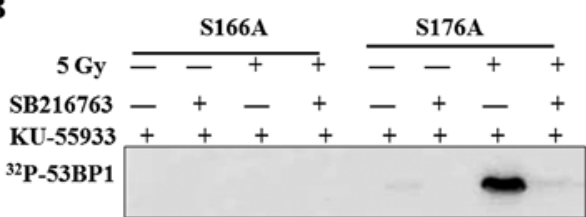

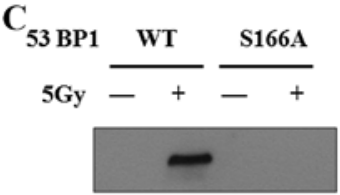

WB: GSK3 $\beta$

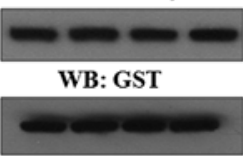

WB: GSK3

Figure 5. Mutation at S166A abrogates the phosphorylation of 53BP1 by GSK3 $\beta$. (A) In vivo co-immunoprecipitation of GSK3 $\beta$ and mutational 53BP1 was performed with the addition of SB216763 or control solvent. Western blot analysis was performed by anti-53BP1 antibody. (B) The ATM kinase inhibitor, KU-55933, was added to the cell medium, and in vivo phosphorylation assay of mutational 53BP1 with or without SB216763 was performed. (C) Immobilized GST-53BP1 proteins were mixed with purified Flag-GSK3 proteins in the presence or absence of IR.

$\mathbf{A}$
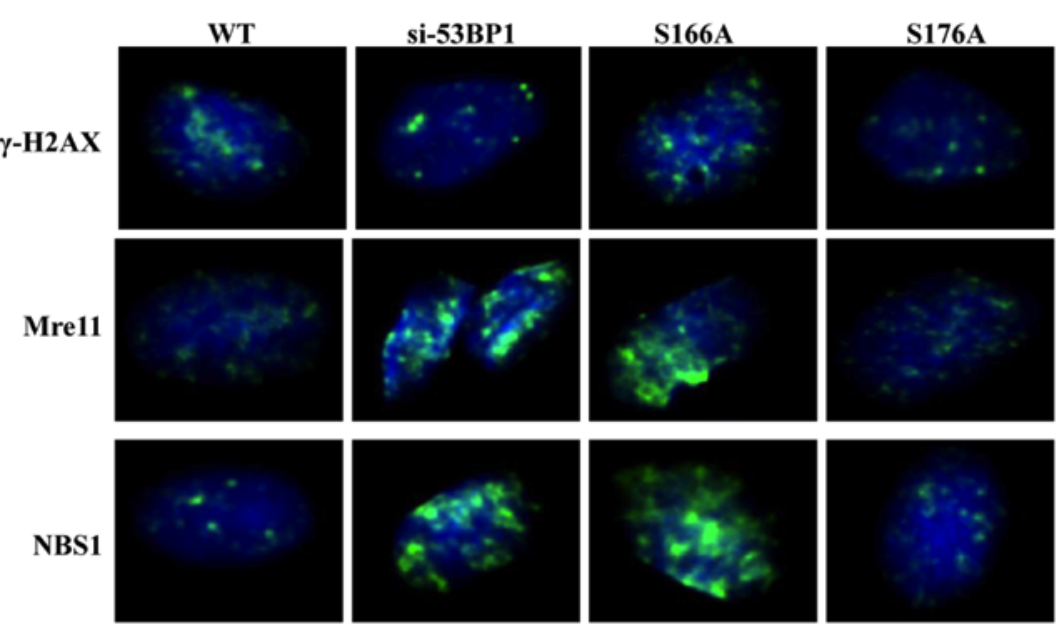

B

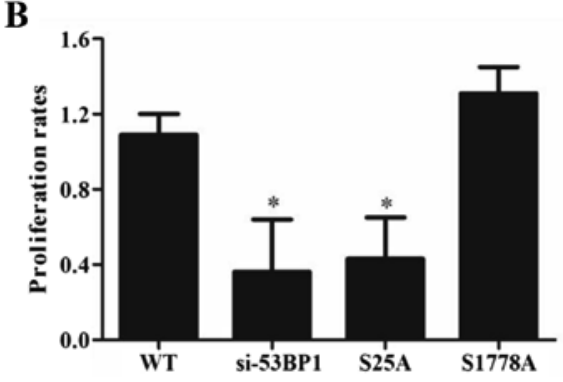

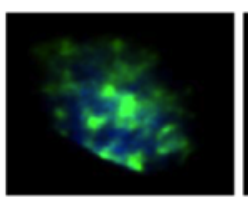
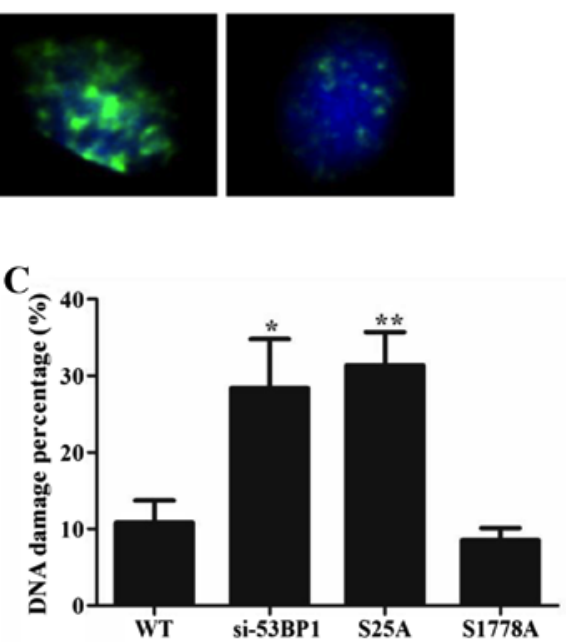

Figure 6. Mutation at S166A abolishes 53BP1-mediated DSB repair. (A) Immunofluorescence staining images of $\gamma$-H2AX, Mre11 and NBS1 in the nucleus of cells treated with wild-type 53BP1, si-53BP1, S166A and S176A mutation of 53BP1. (B) Proliferation rates and (C) DNA damage percentages of U87 cells were assessed. ${ }^{*} \mathrm{P}<0.05$ and ${ }^{* *} \mathrm{P}<0.01$ vs. the wild-type 53BP1 group, as shown by one-way ANOVA with with Bonferroni post-hoc test. Data are the means \pm SEM from 3 independent experiments.

this was further confirmed by the decreased tumor size of the tumors obtained from the mice treated with SB216763 plus IR (Fig. 7D). Furthermore, judged by the body weights and survival curve, treatment with SB216763 plus IR led to a marked recovery in body weight (Fig. 7E) and prolonged the lifespan of mice with brain tumor xenografts compared with those of the control group (Fig. 7C). In addition, as shown in Fig. 7F, a greater number of apoptotic cells was observed following treatment with SB216763 plus IR, as shown by TUNEL labeling. Taken together, based on the qualitative and quantitative analysis above, the inhibition of GSK $3 \beta$ via SB216763 plus IR treatment enhyanced the radiosensitivity of brain tumor xenografts.

Molecular signaling pathway for GSK3 $\beta$ - and 53BP1-mediated DSB repair. The mutual effects between 
A

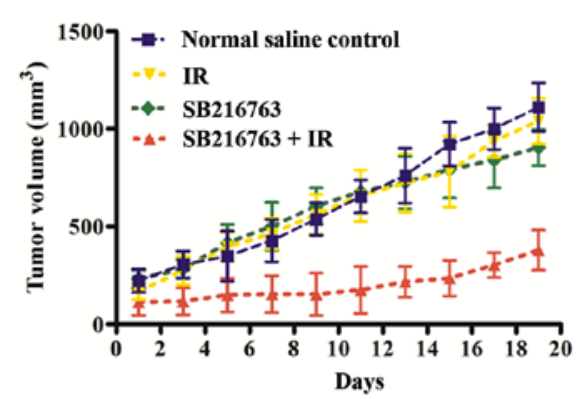

C

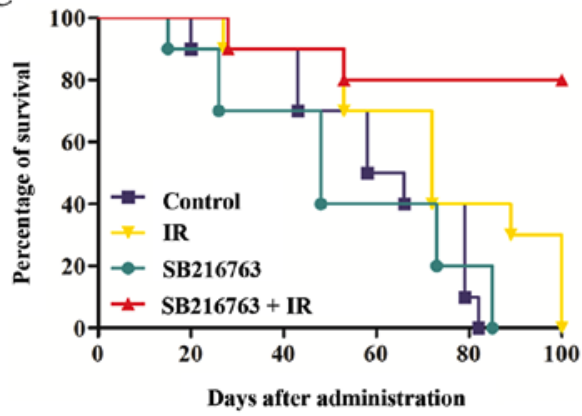

B

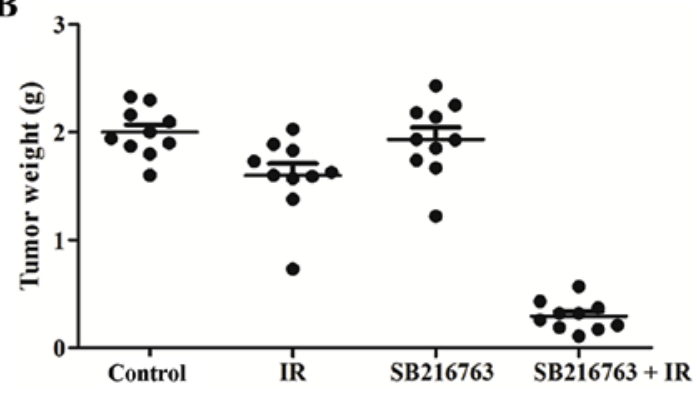

$\mathbf{E}$

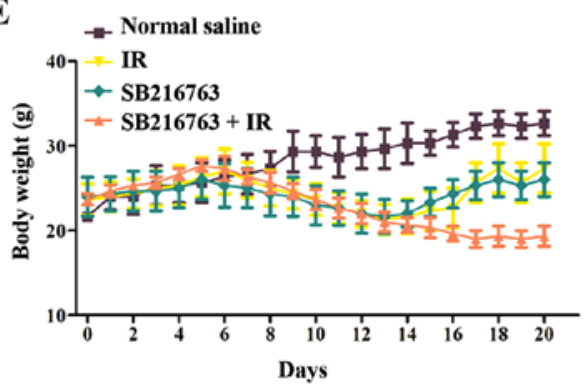

$\mathbf{F}$

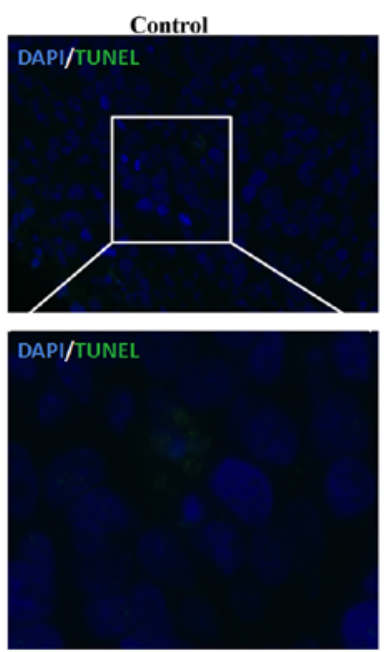

D

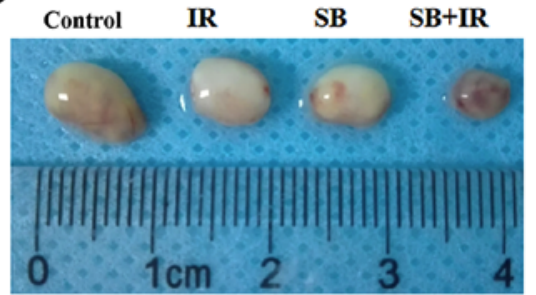

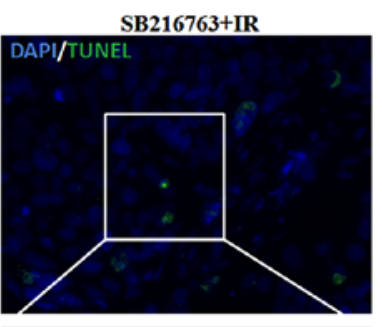

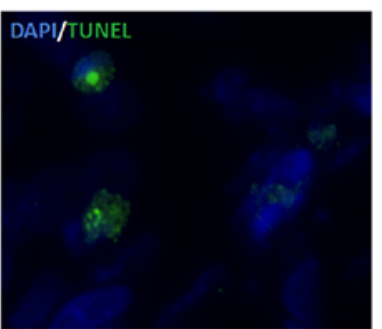

Figure 7. Inhibition of GSK3 enhances the radiosensitivity of brain tumor xenografts. (A) Tumor volume were determined in the control group, ionizing radiation (IR) group, SB216763 group and SB21676 plus IR group ( $\mathrm{n}=10, \mathrm{P}<0.05$ by ANOVA with Bonferroni post-hoc test). (B) Tumor weights of each group $(n=10, P<0.05$ by ANOVA wtih Bonferroni post-hoc test). (C) Survival curve of each group ( $n=10$, P $<0.05$ by Kaplan-Meier). (D) Representative image of xenograft brain tumors. (E) Body weights of each group $(\mathrm{n}=10, \mathrm{P}<0.05$ by ANOVA wtih Bonferroni post-hoc test). (F) Immunofluorescence staining images of TUNEL assay of apoptosis with DNA double-strand breaks in cells of the control group or the SB216763 plus IR group. Data are means \pm SEM from 3 independent experiments.

GSK3 $\beta$ and 53BP1 on DSB repair are shown in Fig. 8. On the basis of IR treatment, GSK3 $\beta$, highly expressed in GBM cells, translocated from the cytoplasm to the nucleus. Co-localized with 53BP1, predominantly existing in the nucleus, GSK3 $\beta$ bound with it by inducing the phosphorylation of 53BP1. As a result, 53BP1-mediated DSB repair was initiated via the stimulation of the MRN complex formation, resulting in the radioresistance of GBM cells. On the other hand, SB216763, a potent and specific GSK $3 \beta$ inhibitor, chemically abrogated the translocation of GSK $3 \beta$ and ultimately led to the apoptosis of GBM cells. In a word, GSK3 $\beta$ and 53BP1 played a central role in DSB repair and the radiosensitivity of GBM cells.

\section{Discussion}

It has been widely acknowledged that with a poor 2-year survival rate, GBM accounts for $80 \%$ of all high-grade primary CNS cancers and is the leading cause of cancer-related mortality $(1,2)$. The standard therapy for GBM consists of surgical resection followed by radiotherapy and chemotherapy (2). Although for patients with malignant glioma, chemotherapy has been given as an adjunct to radiotherapy or before radiotherapy, most of these combined treatments have limited success, and the recurrence of malignant glioma is still presumably high. Therefore, it is well established that 


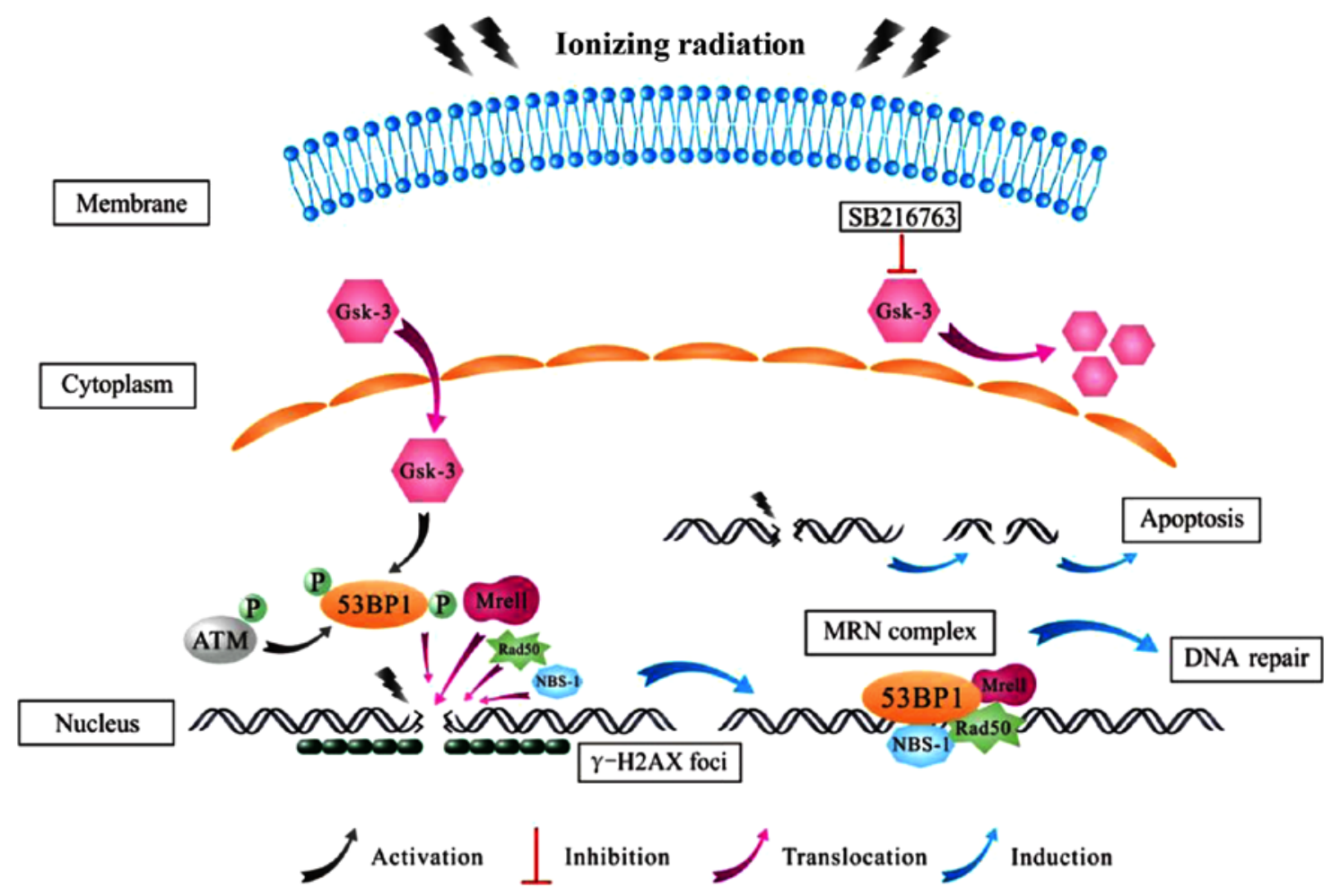

Figure 8. The diagram illustrates the regulation of 53BP1-mediated DSB repair via GSK3 $\beta$. On the basis of exposure to ionizing radiation (IR), GSK3 $\beta$, highly expressed in GBM cells, translocates from the cytoplasm to the nucleus. Co-localized with 53BP1, predominantly existing in the nucleus, GSK3 $\beta$ binds with it by inducing the phosphorylation of 53BP1. As a result, 53BP1-mediated DSB repair is initiated via the stimulation of the MRN complex formation, resulting in the radioresistance of GBM cells. On the other hand, SB216763, a potent and specific GSK3 $\beta$ inhibitor, chemically abrogates the translocation of GSK3 $\beta$ and ultimately leads to the apoptosis of GBM cells.

the development of effective therapeutic agents to improve the radiosensitivity of glioblastoma is of utmost importance. In the present study, we observed the nuclear translocation of GSK $3 \beta$ following IR, and the binding of GSK $3 \beta$ in the nucleus with 53BP1, a key DSB repair protein. Based on these observations, we hypothesized that the IR-induced GSK3 $\beta$ nuclear translocation may activate 53BP1 via phosphorylation at the S/T-Q motif. By cloning different fragments of 53BP1, we found that the phosphorylation site of 53BP1 resides at the N-terminal. The site mutation of Serine to Alanine of S/T-Q motif abrogated the GSK3 $\beta$ induced phosphorylation of 53BP1, which ultimately led to decreased DSB repair. Furthermore, data collected from tumor growth and survival curve analyses using animal models indicated that SB216763, a GSK3 $\beta$ specific inhibitor, enhanced the sensitivity of tumor xenografts to IR and may thus be a potential therapeutic drug for the treatment of GBM.

As a multifunctional serine-threonine $(\mathrm{S} / \mathrm{T})$ protein kinase found in all eukaryotes, GSK3 has a broad regulatory function, including metabolism, cell fate specification, cell division and cell death (34). There are two closely related isoforms, GSK $3 \alpha$ and GSK $3 \beta$, which are encoded by different genes and share nearly identical sequences in their kinase domains. GSK3 $\beta$ interconnects in multiple pathways, such as Wnt, Notch and G-protein coupled receptor (GPCR) signaling $(35,36)$. The aberrant activation of the Wnt and Notch pathways, which is under strict spatial and temporal regulation, has been reported to be tightly associated with tumorigenesis (23). Therefore, by providing cancer cells with a higher self-renewal capacity,
GSK $3 \beta$ play a fundamental and critical role in tumorigenesis on a subset of cancers. It has been shown that the downregulation of GSK3 $\beta$ induces the apoptosis of glioma cells (28) and nuclear GSK3 $\beta$ maintains stem cell-like characteristics of glioblastoma by phosphorylating KDM1A (24). However, the question of whether GSK $3 \beta$ is involved in DSB repair following IR remains unanswered. Thus, in this study, we performed cell proliferation assay, and found that GSK $3 \beta$ inhibitor possessed anti-proliferative capabilities following IR, suggesting that GSK3 $\beta$ may be directly or indirectly involved in the DSB repair signaling pathway. As GSK $3 \beta$ is predominantly a cytosolic protein, we proposed that, to mediate DSB repair, GSK $3 \beta$ should be shifted to the nucleus. Therefore, we focused our study on the cellular distribution of GSK $3 \beta$ following IR. Besides, a previous study on glioblastoma stem cells revealed the critical role of nuclear GSK3 $\beta$ in tumorigenesis (28). Therefore, judged from both the cell immunofluorescence staining images and the western blot analysis data of total nuclear protein, IR induced the translocation of GSK $3 \beta$ from the cytoplasm to the nucleus. Moreover, to elucidate the mechanisms responsible for GSK3 $\beta$-mediated radioresistance, we performed co-immunoprecipitation assay and found the binding of 53BP1 with GSK3 $\beta$, indicating that GSK3 $\beta$ may co-localize with 53BP1. We further hypothesized that the radioresistance of glioblastoma cells was mediated by the activation of 53BP1, which was phosphorylated by GSK3 $\beta$.

53BP1 is an evolutionarily conserved DNA damage checkpoint protein, and is an important regulator of genome stability 
that protects cells against DSBs (37). 53BP1 null mice are viable, but are highly tumor-prone, and are profoundly hypersensitive to IR, probably due to a defect in non-homologous end-joining (NHEJ) (38). Therefore, to study the mechanisms of radioresistance of glioblastoma, it is important to study $53 \mathrm{BP} 1$ as it may play a central role in the DSB repair after IR. It has been demonstrated that as a critical transducer of the DNA damage checkpoint, phosphorylated 53BP1 is re-localized to the nuclear foci upon ionizing irradiation (39). Accumulating evidence indicates that ATM-dependent phosphorylation is a prerequisite for the activation of 53BP1 at sites of DNA breaks and for $\mathrm{G} 2 / \mathrm{M}$ arrest following exposure to irradiation (40). To note, a study on the phosphorylation sites of 53BP1 by ATM revealed that the only known in vivo 53BP1 phosphorylation site was Ser25 (41). Another study on the IR induced phosphorylation of 53BP1 suggested that Thr302, Ser831, Ser166, Ser176/Ser178 and Ser452 may be potential phosphorylation sites as well (32). Moreover, repair factors facilitating DNA repair, such as the Mre11-Rad50-Nbs1 (MRN) complex and phosphorylated $\gamma$-H2AX, are co-localized with 53BP1 (42). This localization is responsible for the recruit of ATM to the DNA damage sites (43). Therefore, whether the binding of GSK3 $\beta$ with 53BP1 causes the phosphorylation, activation and re-localization of 53BP1 remains to be determined. In this study, our in vivo phosphorylation experiments revealed that, in the presence of the ATM inhibitor KU-55933, 53BP1 could still be phosphorylated, further validating our hypothesis that there are additional redundant phosphorylation sites at the $\mathrm{N}$ terminus of 53BP1. Therefore, in the present study, we observed that the inhibition of GSK3 $\beta$ and ATM abrogated the phosphorylation of 53BP1, suggesting that GSK $3 \beta$ was one of the regulators for 53BP1.

For 53BP1, the NH2-terminus contains no functionally defined protein region, but has several Ser-Gln or Thr-Gln (S/T-Q) motifs, which are potential binding and phosphorylation sites for ATM or other kinase. As previously described, GSK3 $\beta$ is a multifunctional Serine-Threonine $(\mathrm{S} / \mathrm{T})$ protein kinase, which means that the NH2-terminus of 53BP1 may be the potential target sites for GSK3 $\beta$. In fact, in this study, by cloning the $\mathrm{NH} 2$-terminus and $\mathrm{COOH}$-terminus fragments of 53BP1 into an expression vector, we clearly demonstrated that the NH2-terminus of 53BP1 becomes hyperphoshorylated in a GSK3 $\beta$-dependent manner in response to IR. Of note, there are approximately 60 amino acids overlapped in both the N1 and $\mathrm{N} 2$ fragments, and we did not observe any phosphorylation of the N2 fragments. Therefore, the phosphorylation sites of 53BP1 may be the N1 fragments from amino acid 1 to 301 . The study by Jowsey et al revealed that Thr302, Ser831, Ser166, Ser176/Ser178 and Ser452 are potential phosphorylation sites of 53BP1 (32); thus, we hypothesized that GSK3 $\beta$ may phosphorylate 53BP1 at Ser166 or Ser176/Ser178. To find the phosphorylation sites of 53BP1 by GSK3 $\beta$, we generated several mutated 53BP1, and found out that when Serine was mutated to Alanine at 166 site, the phosphorylation of 53BP1 was abrogated. The analysis of the DNA repair percentage and cell proliferation rates suggested that the phosphorylation of S166 was sufficient for mediating DNA DSB repair. Alternatively, the mutation of Ser166 to Ala166 markedly inhibited cell proliferation, indicating that 53BP1 phosphorylation at S166 was indispensible for DSB repair and cell survival.
To determine whether GSK3 inhibitor could sensitize tumors to IR, mice bearing established U87 tumors $\left(100 \mathrm{~mm}^{3}\right)$ received either IR or SB216763 treatment prior to IR. On the basis of caliper measurements, although complete tumor regression did not occur in all mice, the mice treated with SB216763 prior to IR exhibited a marked decrease in both tumor volume and tumor weight. Besides, these mice also exhibited a markedly longer survival, indicating that specific GSK3 $\beta$ inhibitor enhanced the sensitivity of glioblastoma cells to IR. Furthermore, immunofluorescence staining images of the DSB breaks by TUNEL staining, which also represents apoptotic cells, clearly indicated that the inhibition of GSK3 $\beta$ inhibited DSB repair following IR. Therefore, based on the oncogenic roles of GSK3 $\beta$ in multiple tumor types, the inhibition of GSK3 may only inhibit tumor progression, but may also sensitize tumor xenografts to radiotherapy in mice and may improve survival.

In conclusion, based on our present findings, it may be possible to reverse the radioresistance of glioma cells with a specific inhibitor of GSK3 $\beta$. Therefore, GSK3 $\beta$ inhibitor may be used as a novel a new drug in the treatment of human gliomas. We anticipate that with the gradual clarification of the molecular mechanisms of radioresistance in glioblastoma, our findings may pave the way in the near future for the development of a novel therapeutic drug by targeting tumor recurrence following radiation and enhancing the sensitivity of tumors to radiotherapy.

\section{Acknowledgements}

This study was supported by the Sichuan Health and Family Planning Commission Funding (16ZD0253), Sichuan National Science Research Funding (2015JY0183), Funding from Sichuan Academy of Medical Science and Sichuan Provincial People's Hospital, and the Sichuan Scientific Research Foundation of the Returned Overseas Chinese Scholars to Dr Yi Wang. The study was also supported by the National Key Specialty Construction Project of Clinical Pharmacy (30305030698).

\section{Competing interests}

The authors declare that they have no competing interests.

\section{References}

1. Killock D: CNS cancer: Molecular classification of glioma. Nat Rev Clin Oncol 12: 502, 2015.

2. Debus J and Abdollahi A: For the next trick: New discoveries in radiobiology applied to glioblastoma. Am Soc Clin Oncol Educ Book 2014: e95-e99, 2014.

3. Kioi M, Vogel H, Schultz G, Hoffman RM, Harsh GR and Brown JM: Inhibition of vasculogenesis, but not angiogenesis, prevents the recurrence of glioblastoma after irradiation in mice. J Clin Invest 120: 694-705, 2010.

4. Felsberg J, Thon N, Eigenbrod S, Hentschel B, Sabel MC, Westphal M, Schackert G, Kreth FW, Pietsch T, Löffler M, et al; German Glioma Network: Promoter methylation and expression of MGMT and the DNA mismatch repair genes MLH1, MSH2, MSH6 and PMS2 in paired primary and recurrent glioblastomas. Int J Cancer 129: 659-670, 2011.

5. Delfino KR, Serão NV, Southey BR and Rodriguez-Zas SL: Therapy-, gender- and race-specific microRNA markers, target genes and networks related to glioblastoma recurrence and survival. Cancer Genomics Proteomics 8: 173-183, 2011.

6. Bao S, Wu Q, McLendon RE, Hao Y, Shi Q, Hjelmeland AB, Dewhirst MW, Bigner DD and Rich JN: Glioma stem cells promote radioresistance by preferential activation of the DNA damage response. Nature 444: 756-760, 2006. 
7. Panier S and Boulton SJ: Double-strand break repair: 53BP1 comes into focus. Nat Rev Mol Cell Biol 15: 7-18, 2014.

8. Schultz LB, Chehab NH, Malikzay A and Halazonetis TD: p53 binding protein 1 (53BP1) is an early participant in the cellular response to DNA double-strand breaks. J Cell Biol 151: 1381-1390, 2000.

9. Squatrito M, Vanoli F, Schultz N, Jasin M and Holland EC: 53BP1 is a haploinsufficient tumor suppressor and protects cells from radiation response in glioma. Cancer Res 72: 5250-5260, 2012.

10. Rappold I, Iwabuchi K, Date T and Chen J: Tumor suppressor p53 binding protein 1 (53BP1) is involved in DNA damage-signaling pathways. J Cell Biol 153: 613-620, 2001.

11. Doble BW and Woodgett JR: GSK-3: Tricks of the trade for a multi-tasking kinase. J Cell Sci 116: 1175-1186, 2003.

12. Hoeflich KP, Luo J, Rubie EA, Tsao MS, Jin O and Woodgett JR Requirement for glycogen synthase kinase-3beta in cell survival and NF-kappaB activation. Nature 406: 86-90, 2000.

13. Sugden PH, Fuller SJ, Weiss SC and Clerk A: Glycogen synthase kinase 3 (GSK3) in the heart: A point of integration in hypertrophic signalling and a therapeutic target? A critical analysis. $\mathrm{Br}$ J Pharmacol 153 (Suppl 1): S137-S153, 2008.

14. Gao C, Hölscher C, Liu Y and Li L: GSK3: A key target for the development of novel treatments for type 2 diabetes mellitus and Alzheimer disease. Rev Neurosci 23: 1-11, 2011.

15. Kim L and Kimmel AR: GSK3, a master switch regulating cell-fate specification and tumorigenesis. Curr Opin Genet Dev 10: 508-514, 2000.

16. Luo J: Glycogen synthase kinase 3beta (GSK3beta) in tumorigenesis and cancer chemotherapy. Cancer Lett 273: 194-200, 2009.

17. Marchand B, Arsenault D, Raymond-Fleury A, Boisvert FM and Boucher MJ: Glycogen synthase kinase-3 (GSK3) inhibition induces prosurvival autophagic signals in human pancreatic cancer cells. J Biol Chem 290: 5592-5605, 2015.

18. Shakoori A, Ougolkov A, Yu ZW, Zhang B, Modarressi MH, Billadeau DD, Mai M, Takahashi Y and Minamoto T: Deregulated GSK3beta activity in colorectal cancer: Its association with tumor cell survival and proliferation. Biochem Biophys Res Commun 334: 1365-1373, 2005.

19. Yook JI, Li XY, Ota I, Hu C, Kim HS, Kim NH, Cha SY, Ryu JK, Choi YJ, Kim J, et al: A Wnt-Axin2-GSK3beta cascade regulates Snail1 activity in breast cancer cells. Nat Cell Biol 8: 1398-1406, 2006.

20. Mulholland DJ, Dedhar S, Wu H and Nelson CC: PTEN and GSK3beta: Key regulators of progression to androgen-independent prostate cancer. Oncogene 25: 329-337, 2006

21. Miyashita K, Kawakami K, Nakada M, Mai W, Shakoori A Fujisawa H, Hayashi Y, Hamada J and Minamoto T: Potential therapeutic effect of glycogen synthase kinase 3beta inhibition against human glioblastoma. Clin Cancer Res 15: 887-897, 2009.

22. Kotliarova S, Pastorino S, Kovell LC, Kotliarov Y, Song H, Zhang W, Bailey R, Maric D, Zenklusen JC, Lee J, et al: Glycogen synthase kinase-3 inhibition induces glioma cell death through c-MYC, nuclear factor-kappaB, and glucose regulation. Cancer Res 68: 6643-6651, 2008.

23. Ougolkov AV, Fernandez-Zapico ME, Bilim VN, Smyrk TC, Chari ST and Billadeau DD: Aberrant nuclear accumulation of glycogen synthase kinase-3beta in human pancreatic cancer: association with kinase activity and tumor dedifferentiation. Clin Cancer Res 12: 5074-5081, 2006.

24. Zhou A, Lin K, Zhang S, Chen Y, Zhang N, Xue J, Wang Z, Aldape KD, Xie K, Woodgett JR, et al: Nuclear GSK3 $\beta$ promotes tumorigenesis by phosphorylating KDM1A and inducing its deubiquitylation by USP22. Nat Cell Biol 18: 954-966, 2016.
25. Allen M, Bjerke M, Edlund $\mathrm{H}$, Nelander S and Westermark B: Origin of the U87MG glioma cell line: Good news and bad news. Sci Transl Med 8: 354re3, 2016.

26. Boyé K, Pujol N, D Alves I, Chen YP, Daubon T, Lee YZ, Dedieu S, Constantin M, Bello L, Rossi M, et al: The role of CXCR3/LRP1 cross-talk in the invasion of primary brain tumors. Nat Commun 8: 1571, 2017.

27. Volpin F, Casaos J, Sesen J, Mangraviti A, Choi J, Gorelick N, Frikeche J, Lott T, Felder R, Scotland SJ, et al: Use of an anti-viral drug, Ribavirin, as an anti-glioblastoma therapeutic. Oncogene 36: 3037-3047, 2017

28. Korur S, Huber RM, Sivasankaran B, Petrich M, Morin P Jr, Hemmings BA, Merlo A and Lino MM: GSK3beta regulates differentiation and growth arrest in glioblastoma. PLoS One 4: e7443, 2009.

29. Beckner ME, Gobbel GT, Abounader R, Burovic F, Agostino NR, Laterra J and Pollack IF: Glycolytic glioma cells with active glycogen synthase are sensitive to PTEN and inhibitors of PI3K and gluconeogenesis. Lab Invest 85: 1457-1470, 2005.

30. Bijur GN and Jope RS: Glycogen synthase kinase- $3 \beta$ is highly activated in nuclei and mitochondria. Neuroreport 14: 2415-2419, 2003.

31. Williams RS, Williams JS and Tainer JA: Mre11-Rad50-Nbs1 is a keystone complex connecting DNA repair machinery, doublestrand break signaling, and the chromatin template. Biochem Cell Biol 85: 509-520, 2007.

32. Jowsey P, Morrice NA, Hastie CJ, McLauchlan H, Toth R and Rouse J: Characterisation of the sites of DNA damage-induced 53BP1 phosphorylation catalysed by ATM and ATR. DNA Repair (Amst) 6: 1536-1544, 2007.

33. Harding SM, Coackley C and Bristow RG: ATM-dependent phosphorylation of 53BP1 in response to genomic stress in oxic and hypoxic cells. Radiother Oncol 99: 307-312, 2011.

34. Jope RS and Johnson GV: The glamour and gloom of glycogen synthase kinase-3. Trends Biochem Sci 29: 95-102, 2004.

35. Wu D and Pan W: GSK3: A multifaceted kinase in Wnt signaling. Trends Biochem Sci 35: 161-168, 2010.

36. Hur EM and Zhou FQ: GSK3 signalling in neural development. Nat Rev Neurosci 11: 539-551, 2010.

37. Abraham RT: Checkpoint signalling: Focusing on 53BP1. Nat Cell Biol 4: E277-E279, 2002.

38. Ward IM, Minn K, van Deursen J and Chen J: p53 binding protein 53BP1 is required for DNA damage responses and tumor suppression in mice. Mol Cell Biol 23: 2556-2563, 2003.

39. Wang B, Matsuoka S, Carpenter PB and Elledge SJ: 53BP1, a mediator of the DNA damage checkpoint. Science 298: 1435-1438, 2002.

40. DiTullio RA Jr, Mochan TA, Venere M, Bartkova J, Sehested M, Bartek $\mathrm{J}$ and Halazonetis TD: 53BP1 functions in an ATM-dependent checkpoint pathway that is constitutively activated in human cancer. Nat Cell Biol 4: 998-1002, 2002.

41. Ward IM, Minn K, Jorda KG and Chen J: Accumulation of checkpoint protein 53BP1 at DNA breaks involves its binding to phosphorylated histone H2AX. J Biol Chem 278: 19579-19582, 2003.

42. Anderson L, Henderson C and Adachi Y: Phosphorylation and rapid relocalization of 53BP1 to nuclear foci upon DNA damage. Mol Cell Biol 21: 1719-1729, 2001.

43. Xia Z, Morales JC, Dunphy WG and Carpenter PB: Negative cell cycle regulation and DNA damage-inducible phosphorylation of the BRCT protein 53BP1. J Biol Chem 276: 2708-2718, 2001.

This work is licensed under a Creative Commons Attribution-NonCommercial-NoDerivatives 4.0 International (CC BY-NC-ND 4.0) License. 